\title{
Democracia y sorteo de cargos
}

\author{
Democracy and drawing of public office
}

SEBASTIÁN LINARES*

\begin{abstract}
Resumen: Se contrastan las virtudes democráticas de las elecciones populares con las del sorteo de cargos, y se argumenta que las elecciones populares (aunque también los referéndums activados por la ciudadanía) exhiben mejores credenciales morales para arrogarse la legitimidad y autoridad final en un sistema político. Se rescata el carácter complementario del sorteo de cargos y se discuten algunas propuestas mixtas que combinan el sorteo de cargos con las elecciones populares. Finalmente, se propone un nuevo sistema de democracia directa -activado por la ciudadanía- que hace un uso inteligente de las asambleas de sorteados. Se argumenta que bajo este último formato las asambleas de sorteados están capacitadas para fijar un nuevo horizonte de legitimidad democrática.

Palabras clave: democracia, elecciones, sorteo, democracia directa, asambleas de sorteados.
\end{abstract}

\begin{abstract}
The democratic virtues of popular elections are contrasted with those of the lottery, and it is argued that popular elections (and also citizens' activated referendums) exhibit better moral credentials to claim legitimacy and ultimate authority in a political system. The article vindicates the complementary nature of lotteries and discusses some mixed proposals that combine elections with lotteries. Finally, a new system of citizen activated mechanisms of direct democracy is proposed, in which citizen's assemblies (recruited by lot) play an important role. It is argued that this new model is able to set a new horizon of democratic legitimacy.
\end{abstract}

Key words: democracy, elections, sortition, direct democracy, citizen's assemblies.

\section{Introducción}

Cuando planteamos la inquietud de saber cuál institución es más democrática, si las elecciones populares o el sorteo de cargos, inevitablemente se plantea la pregunta de qué es la democracia. En la ciencia política contemporánea parece existir un consenso en que el concepto de democracia refiere a un sistema de reglas de acceso al poder caracterizado por elecciones populares libres, transparentes, inclusivas (una persona adulta, un voto) y compe-

Fecha de recepción: 23/05/2017. Fecha de aceptación: 19/09/2017.

* Investigador del Consejo Nacional de Investigaciones Científicas y Técnicas de Argentina (CONICET) y trabaja en el Instituto de Investigaciones Económicas y Sociales del Sur (UNS-CONICET). Sus principales líneas de investigación son: Ciencias Políticas, Teoría de la democracia, Organizaciones y partidos políticos, Democracia deliberativa, Democracia participativa, Política judicial. Recientemente ha publicado el libro Democracia participativa epistémica, Marcial Pons, Madrid, 2017; y un artículo titulado "Democracy, epistemic value, and political equality: a new model of epistemic participatory democracy", Ethics and Politics, 19 (1), Monographica II, pp. 247-283. Contacto: seblinares@iiess-conicet.gob.ar 
titivas. Los politólogos por regla general no consideran que el sorteo pueda ser democrático sencillamente porque la palabra democracia hace referencia descriptiva a las elecciones. El sorteo podrá ser todo lo justo o imparcial o igualitario que se quiera, pero no reúne ninguna de las condiciones del concepto de democracia definido en esos términos. En el terreno de filosofía política, en cambio, la cuestión es algo más compleja. Las elecciones populares libres y competitivas son democráticas porque satisfacen algunos valores que caracterizan la "idea" filosófica de democracia. Luego, en este terreno sí parece tener sentido plantearse la inquietud de si el sorteo honra esos valores que dan sentido a la idea o el ideal regulativo de democracia.

¿Cuál es más democrático: el sorteo o las elecciones populares? La respuesta depende de cuáles creamos que sean los valores que justifican o constituyen la idea de democracia. He sostenido (véase Linares, 2017) que son tres los valores de los que pende el ideal regulativo de la democracia: el valor de la igualdad de trato, el valor de la libertad de elección, y el valor del conocimiento, o valor epistémico. Este último se traduce en la capacidad del procedimiento de toma de decisiones para discernir el elenco de opciones correctas o aceptables y escoger una buena alternativa, aunque no sea la mejor disponible. Ninguno de estos valores, considerados aisladamente, puede justificar por sí sólo un sistema democrático. Por ejemplo, si tomamos el valor de la libertad de elección, y buscamos maximizar tanto como se puedan las oportunidades de elección y el menú de alternativas disponible, entonces sólo la anarquía quedaría justificada (es decir, un sistema donde ninguna decisión colectiva sería obligatoria a menos que sea consentida por cada persona). Si tomamos sólo la igualdad de trato, entonces no sabríamos si elegir entre el sorteo puro o un sistema de elecciones populares completamente inclusivo (donde incluso los menores e incapaces tendrían derecho a voto). Y si nos centramos sólo en el valor epistémico, entonces quedaría justificada la epistocracia, o el gobierno de los expertos (Brennan, 2014, 2016). De ello se sigue que las concepciones democráticas puramente procedimentalistas (ancladas en la igualdad de trato y la libertad de elección) y las puramente epistémicas, proveen una justificación insuficiente. No es posible justificar la democracia sin una dimensión epistémica, pero tampoco es posible fundar la democracia sólo en la dimensión epistémica. Una concepción plausible de democracia necesariamente tiene que ser mixta o plural (véase también Martí, 2006a y 2006b).

Volvamos a la pregunta que nos concierne, y analicemos las credenciales de las elecciones y el sorteo a la luz de los valores recién mencionados. Pues bien, si consideramos únicamente el valor de la igualdad de trato, las elecciones populares inclusivas y el sorteo de cargos se arrogan credenciales moralmente equivalentes, pues ambas tratan con igualdad a todos sin discriminaciones irritantes. Es verdad que las elecciones, al tratar con igualdad formal a todos, permite que las desigualdades reales (en riqueza y educación) se trasladen a la política. Mientras que todos están en pie de igualdad para escoger representantes, no todos están en pie de igualdad para ser elegidos: quienes tienen más recursos, vínculos, acceso a los medios de comunicación, tienen más probabilidades de ganar un escaño. El reconocimiento de esta circunstancia da origen a una de las primeras críticas importantes a las elecciones: las elecciones populares tienen un sesgo elitista que no posee el sorteo de cargos públicos. Ahora bien, esta crítica es atendible, pero no logra dimensionar adecuadamente los riesgos del sorteo de cargos. Si bien es cierto que las 
elecciones populares tienen o pueden tener un sesgo elitista, también es posible pensar que el sorteo de cargos sea igual de vulnerable a la desigual influencia de la riqueza y el acceso a los medios de comunicación. No existe ninguna razón para pensar que una única asamblea de sorteados permanente vaya a estar completamente blindada a la corrupción, la presión de los grupos de interés, y el poder del dinero, más teniendo en cuenta que los sorteados no estarán atados a ninguna promesa pública.

Si consideramos la libertad de elección, es evidente que la elección popular brinda oportunidades más amplias para ejercerla que el sorteo de cargos. En este terreno las elecciones salen victoriosas: y es que cuando votamos por un representante estamos escogiendo entre diversas alternativas políticas, aun cuando nuestras preferencias queden en minoría. En cambio, el sorteo de cargos no da ninguna posibilidad a nadie de ejercer la libertad de elección: la adjudicación de cargos es obra de la suerte. Esta consideración pone al sorteo de cargos en serios aprietos. Existe una larga tradición del pensamiento político que asocia a la democracia con la libertad, y en particular con la libertad colectiva o el autogobierno: la capacidad de una sociedad de escoger su propio destino y de establecer sus propias reglas de convivencia. La bandera del autogobierno está tan arraigada en el pensamiento democrático que resulta muy difícil entender cómo es que un sistema únicamente basado en el sorteo de cargos puede responder con éxito a ese reclamo tan básico y fundamental: el de que las decisiones que nos gobiernan sean nuestras no en un sentido hipotético, sino en un sentido directo. Tener una misma probabilidad de acceder a un cargo público no es, sin más, democrático, si solo unas pocas personas alcanzan esas funciones a lo largo de una generación. Un dictador escogido por sorteo nunca será democrático, aunque el sistema honre la igualdad de trato.

Es difícil ver cómo, frente a una decisión vinculante tomada por una asamblea de sorteados, un ciudadano puede sentirla como propia en algún sentido relevante. Un ciudadano opositor a un gobierno electo siempre puede pensar: "no estoy de acuerdo con esta decisión, pero he tenido iguales oportunidades para participar en la elección del gobierno y lamentablemente he quedado en minoría por un tiempo, tal vez porque no supe persuadir a otros de la validez y fuerza de mis convicciones". En un esquema de sorteo de cargos, el ciudadano opositor en cambio debería pensar lo siguiente: "No estoy de acuerdo con esta decisión, pero he tenido iguales oportunidades para ser escogido por la suerte en el gobierno, aunque lamentablemente no haya salido escogido esta vez y sepa que las probabilidades de salir sorteado alguna vez son ínfimas. No sé si la decisión se corresponde con las preferencias de la mayoría, ni importa si mis convicciones resultan persuasivas, yo debo aceptar la decisión porque la suerte trata con igualdad a todos". Puede que a alguien este argumento le siga resultando atractivo; yo lo encuentro del todo bizarro ${ }^{1}$.

Debemos considerar ahora cómo se desempeñan ambos métodos de selección desde un punto de vista epistémico. Aquí voy a discutir tres argumentos: el argumento de igual competencia epistémica, el argumento de la voluntad general hipotética, y el argumento de la diversidad cognitiva.

1 El argumento parece tener asidero empírico. En un experimento sobre cooperación entre granjeros sobre bienes comunes se demostró que aquellos granjeros a los que se les permitía seleccionar un monitor centralizado tenían un desempeño mejor y percibido como más legítimo que aquellos en los que el monitor era seleccionado por azar (Baldasarri y Grossman, 2011). 


\subsection{La igual competencia epistémica}

Un primer argumento diría que el sorteo de cargos públicos se justifica cómo única forma de gobierno porque todas las personas poseen una igual competencia epistémica para tomar decisiones políticas vinculantes. Si las personas no se distinguen entre sí por sus aportes epistémicos, y estos aportes tienden a ser en promedio significativos, entonces el sorteo de cargos permitiría respetar la igualdad al mismo tiempo que mantener el compromiso epistémico con la toma de buenas decisiones. El problema de este argumento es que se basa en una premisa falsa: la premisa de que todos poseen iguales competencias técnicas para tomar decisiones en sociedades complejas. Una cosa es decir que todos deben poseer iguales oportunidades para participar en pie de igualdad porque están comprometidos fines y valores morales en la decisión, y otra cosa es decir que todos deben tener una igual probabilidad de salir sorteados porque todos son igual de competentes. La primera afirmación parte de una premisa normativa que es atendible. La segunda afirmación, en cambio, parte de una premisa empíricamente falsa. Que todas las decisiones políticas de importancia involucren una dimensión moral -respecto de la cual estamos en desacuerdo- justifica el que todos tengamos un derecho a elegir en pie de igualdad, no un derecho a participar de un sorteo. Nadie tiene derecho a imponerme una decisión que yo juzgo incorrecta sólo porque él tuvo la suerte de salir sorteado. Ese no es un argumento que pueda derrotar mi igual interés por participar en la elección de fines morales involucrados en la decisión.

Si creemos que todos los ciudadanos tienen un derecho igual a ejercer la función pública, sin que quepa discriminar otras razones para preferir entre ellos, entonces podría resultar justo adjudicar los cargos por sorteo. Sin embargo, resulta muy dudoso que no dispongamos de parámetros epistémicos para juzgar los méritos de los candidatos o de las políticas que estos proponen, aún cuando éstos sean controvertidos. Si entendemos que la distribución de funciones debe estar asociada al mérito, la competencia o la virtud (y ello con independencia de que estemos en desacuerdo respecto de que significan estas palabras), y entendemos que la distribución de esas virtudes es desigual, entonces el sorteo no se justifica, porque impide que esas razones valiosas ejerzan su debida influencia.

Las elecciones populares y las votaciones, en cambio, sí pueden tener la propiedad de dejar que las razones sustantivas ejerzan una significativa influencia en quién resultará escogido. Este es un punto crucial: una razón de por qué el sorteo de cargos no tiene sentido epistémico en las democracias liberales como mecanismo exclusivo radica en que el sorteo rompe la conexión entre la decisión legislativa y los proyectos políticos entre los cuales pueden elegir los ciudadanos. En unas elecciones representativas se elige entre partidos o candidatos (que proponen paquetes de políticas con sustento en razones), mientras que en un sorteo no hay posibilidad de establecer una conexión entre lo que hará el agraciado y lo que quiere la sociedad.

Ahora bien, uno podría traer a la palestra una tesis más débil, según la cual las personas son igual de competentes para juzgar los expertos. Para justificar el sorteo como único método -diría el argumento- solo haría falta la igual capacidad para juzgar la competencia de los expertos. El problema que tiene este argumento es que tampoco alcanza a desbaratar la primacía de las elecciones populares, porque si todos son igual de competentes para juz- 
gar a los expertos, entonces por la misma razón se justificaría un sistema donde todas las personas pudieran, después de oír las razones de los expertos, decidir quién debe gobernar, o qué alternativa de decisión tomar en conjunto.

\subsection{El argumento de la voluntad general hipotética}

Se ha dicho que una de las virtudes del sorteo, cuando se usa para la selección de un número amplio de personas, es la de asegurar la representación descriptiva de la población (Fishkin, 2009; Sintomer, 2010a, 2010b; Zakaras, 2010). Según esta línea de pensamiento, el sorteo de una asamblea hace posible que los rasgos descriptivos que identifican a las personas de una población (género, etnia, cultura, clase social, lugar de residencia, educación, edad, profesión, actitudes valorativas, entre otros) estén presentes, en igual proporción, dentro de la muestra seleccionada por azar. El efecto en la representatividad de la muestra es el resultado mecánico del carácter aleatorio del sorteo: dado que todos cuentan con una igual probabilidad de salir sorteados, la ley de los grandes números hace posible que los rasgos descriptivos más salientes salgan sorteados en igual proporción a los de la población general.

Afianzados en esta idea, muchos autores defienden el sorteo de cargos apelando, en primer lugar, al efecto del sorteo sobre la representación descriptiva, y, en segundo lugar, a la posibilidad de inferir, de la representación descriptiva, una voluntad general hipotética². Debemos plantearnos entonces la pregunta más ambiciosa: ¿el argumento de la voluntad hipotética justificaría una única asamblea de sorteados vinculante?

Creo que existen dos problemas fundamentales en esta tesis. El primer problema es de índole filosófico, y aparece cuando nos preguntamos si es razonable presumir la "representación descriptiva" de toda la sociedad en su conjunto. Desde una perspectiva filosófica resulta muy controvertido pensar en que una asamblea de sorteados pueda "representar", a escala pequeña, todas las actitudes, rasgos, valores, preferencias, y perspectivas del público general. Muchas personas se consideran seres irrepetibles, con valores, sentimientos y pensamientos únicos, algunos puede que hasta incomunicables. De hecho, un enfoque de la psicología considera que los estados mentales de cada uno son el resultado de experiencias, memorias, ideas, influencias que ninguna otra persona podrá duplicar. Siempre resultará muy polémico, desde un punto de vista filosófico, reclamar a estas personas obediencia a las leyes por el hecho de haber estado "descriptivamente" representadas en la muestra.

El segundo problema emerge cuando consideramos que los sorteados, después de deliberar, dejan de representar a la población general, para transformarse en expertos sobre una cuestión particular (Parkinson, 2006, 8; Lafont, 2014: 11). Es verdad que uno podría sostener que incluso después de deliberar siguen representando a una población ya no real, sino hipotética. Pero el problema es que el carácter hipotético de esa población depende fuertemente de que seamos capaces de mostrar que los argumentos vertidos son convincentes para la mayoría de esa población hipotética, porque se supone que es la fuerza moral del

2 El principal promotor de la causa en la actualidad es James Fishkin. Sin embargo, Fishkin no extrae implicaciones institucionales robustas de esa tesis. Así, todo su proyecto está dirigido a convertir a las asambleas de sorteados en una fuente de "consulta" para las autoridades electas (Fishkin, 2009: 13). 
mejor argumento lo que importa, no la dependencia causal de los mensajes con las variables o rasgos sociológicos de la muestra. Pero aquí aparece el talón de Aquiles del argumento: cuando se trata de argumentar acerca de la mejor alternativa, se supone que la validez del argumento "no depende" (ni debería depender) causalmente de ningún rasgo o propiedad usada para la estratificación, ya que las razones sustantivas de la deliberación y los factores representados en la muestra se encuentran en planos inconmensurables: el primero es normativo, el segundo es descriptivo o, si se quiere, inferencial. Mientras que la estadística intenta hallar una muestra de la que poder inferir rasgos en la población general, la deliberación intenta encontrar los mejores argumentos de apoyo a una alternativa de decisión. Los méritos sustantivos de cada decisión han de ser evaluados a partir de los parámetros sustantivos externos que aplican a esa decisión, no a partir de parámetros sociológicos. Y el mérito descriptivo de ser una decisión que podría ser válida para una muestra representativa de una población hipotética no parece, desde un punto de vista normativo, más robusto que el mérito de ser la "mejor" alternativa, o el mérito de ser la alternativa preferida realmente por la mayoría de la población.

\subsection{El argumento de la diversidad cognitiva}

Existe una tercera línea de justificación epistémica del sorteo de cargos que ha sido articulada por Hélène Landemore. Según la profesora de Yale, las asambleas de sorteados se justifican por la contribución epistémica que pueden hacer para la solución de problemas comunes y la formulación de predicciones. Así, el hecho matemático es que un grupo de personas con una competencia general mediocre, pero con perspectivas y enfoques heurísticos diversos, puede llegar a mejores soluciones que un grupo igual de numeroso con una competencia general superior (Hong y Page, 2001, 2004; Page, 2007a, 2007b). En cambio, cuando se trata de hacer predicciones, el hecho matemático es que la diversidad cognitiva desempeña un papel igual de importante que la competencia (Hong y Page, 2012). Es a la luz de estas premisas, sostiene Landemore, que el sorteo de cargos podría propiciar la diversidad cognitiva dentro de un sistema político. Puesto que no sabemos de antemano, y somos incapaces de saberlo, qué perspectivas y herramientas heurísticas importan, debido a la complejidad, variedad e imprevisibilidad de los temas y problemas que se discuten, debemos permitir tanta diversidad cognitiva como sea posible (Landemore, 2013a, 2013b). No está claro que Landemore defienda la instauración de una asamblea de sorteados como única forma de gobierno, pero aquí será útil considerar esa posibilidad para ver hasta dónde llega su argumento.

Esta línea de justificación hipotética enfrenta dos grandes problemas: el primero es un problema de escala, y el segundo es un problema de especificación. El problema de escala aparece cuando nos percatamos que la diversidad cognitiva que importa tiene que estar orientada a la solución del problema. Saber cómo se hacen las mejores pizzas, no es relevante ni útil para resolver el problema de la escasez de viviendas, ni el problema de la drogadicción juvenil, por poner un ejemplo sarcástico. Las asambleas de sorteados tienen un límite natural en la escala: un número de personas que haga posible el intercambio de propuestas, razones, objeciones y evidencias. Cabe pensar que ese número siempre será muy inferior al número de problemas complejos y sofisticados para cuya solución óptima 
se requiere de una perspectiva o enfoque heurístico muy específico que no ha sido seleccionado por sorteo. El límite de la escala plantea serias dudas sobre la posibilidad de que una asamblea de sorteados pueda hacer valer la diversidad cognitiva que importa en cada caso.

El segundo problema es de especificación. Una de las condiciones del teorema de Hong y Page es que los participantes sean mínimamente inteligentes. Pero la pregunta es: ¿dónde reside el umbral de competencia epistémica mínima para que la diversidad cognitiva de una asamblea de sorteados pueda desplegar sus virtudes instrumentales? No está nada claro (o al menos siempre será objeto de controversias razonables) que en condiciones reales una asamblea de sorteados reúna esa condición mínima para que apliquen las implicaciones del teorema de Hong y Page.

\section{Propuestas mixtas de uso del sorteo}

He dado razones para defender la primacía de las elecciones populares porque están mejor pertrechadas para honrar los valores inherentes al ideal democrático. Sin embargo, ello no impide reconocer que el sorteo de cargos puede tener un lugar complementario a las elecciones populares. En la última década se ha desarrollado una extensa literatura de ingeniería constitucional que plantea con rigor minucioso diversas propuestas complementarias de uso del sorteo en las democracias contemporáneas. Aquí me voy a centrar en las dos propuestas más interesantes. Hablaré así de las asambleas de sorteados puntuales y consultivas y de las cámaras altas de sorteados.

\subsection{Asambleas de sorteados "ad hoc" y consultivas}

Las asambleas de sorteados "ad hoc" y consultivas no vienen a sustituir las elecciones ni están llamadas a ocupar un lugar permanente en el sistema político democrático. Son resortes consultivos que pueden "complementar" el proceso de toma de decisiones, y que sirven de fuente de consulta para los representantes o para la ciudadanía. Estas asambleas tienen las siguientes características: a) se trata de asambleas convocadas para tratar un tema puntual, b) los ciudadanos son seleccionados por sorteo, o el sorteo al menos ocupa un papel relevante en la selección y c) los resultados de las asambleas son meramente exhortativos, es decir, sirven como fuente de consulta para las autoridades políticas. Fuera de estas similitudes, existen notables diferencias en las propuestas. Una clasificación útil que permitirá explorar esas diferencias distingue el tipo de asambleas según la etapa del proceso en la que intervienen: a) definición del problema, b) identificación de alternativas y propuestas, c) información al ciudadano, y d) control de la instrumentación. Dependiendo de la fase en que se convocan estas asambleas puntuales, tendríamos distintas modalidades, que pasamos a describir.

Las conferencias de prioridades se convocan expresamente con la finalidad de "identificar" asuntos problemáticos. A estas conferencias se les pide que deliberen sobre los problemas más acuciantes o urgentes de la sociedad. La finalidad es la de detectar asuntos problemáticos y detectar un orden de prioridades entre esos asuntos. Del mismo modo que a los ciudadanos, en las encuestas tradicionales, se les pide que jerarquicen diferentes proble- 
mas sociales que los aquejan, en las conferencias de prioridades se les pide a los ciudadanos sorteados que expresen sus ordenes de prioridades antes y después de las deliberaciones.

Los paneles de diseño son grupos de ciudadanos sorteados que intervienen en una fase intermedia entre la identificación de los problemas y la propuesta de soluciones alternativas. Cuando algún legislador, o un grupo de ciudadanos, buscan presentar una propuesta de reforma para dar respuesta a determinado problema, antes de presentarla en sede administrativa o plantearla ante la asamblea legislativa, puede considerar oportuno abrir una fase de diálogo entre los ciudadanos. El objetivo de esta iniciativa es el de buscar alternativas y reforzar la legitimidad de dicha propuesta en las instancias decisoras.

Se denominan Asambleas de Ciudadanos en sentido estricto a todas aquellas que son convocadas por sorteo para deliberar y emitir una opinión sobre alguna propuesta de reforma ya presentada en la Legislatura o sometida a referéndum, pero aún no votada. La Asamblea convocada tiene el cometido de evaluar las reformas propuestas, deliberar sobre las distintas alternativas, proponer enmiendas, y llegar a una decisión exhortativa. La decisión equivale a una recomendación ciudadana, que se presentará a la Legislatura y se publicará en la prensa y los medios de comunicación, o que servirá como fuente de consulta para los votantes en referéndum ${ }^{3}$.

Los jurados de información ciudadana son grupos de 20 ciudadanos sorteados que se convocan para deliberar, por pocos días, sobre los méritos de los candidatos o sobre propuestas que habrán de ser votadas en referéndum. El propósito último del jurado no es el de tomar una decisión, sino el de "informar" adecuadamente a los ciudadanos que tienen que votar por una u otra opción. La decisión se plasmará en un boletín informativo, de una carilla, que entregará a los votantes. Se busca que los votantes desinformados, antes de depositar la papeleta en la urna, puedan leer con claridad las conclusiones a las que llegó dicha asamblea de ciudadanos, así como las razones principales que sustentan dichas conclusiones ${ }^{4}$.

Por último, tenemos los llamados jurados de control de políticas públicas, que son asambleas de sorteados que se convocan con carácter permanente para "controlar" la implementación de políticas públicas aprobadas (en referéndum, o por la Legislatura). Hasta el momento no ha habido experiencias de este tipo, pero algunos autores plantean la posibilidad de instaurar jurados de control de instrumentación de las políticas públicas aprobadas en referéndum cuando la Legislatura o el gobierno está en desacuerdo con las mismas, como un instrumento eficaz para evitar que el gobierno desvirtúe, a través de la reglamentación, el espíritu de la norma aprobada (véase Garret y McCubbins, 2007).

3 Como modelo pionero de Asamblea de Ciudadanos es común citar a la de British Columbia, en Canadá, que tuvo lugar en 2004. Fue convocada por el gobierno para que discutiera alternativas de reforma al sistema electoral del estado local. Su recomendación fue sometida a consideración de los residentes en British Columbia en un plebiscito concurrente con las elecciones de 2005. La propuesta fracasó porque sólo se obtuvo el $57,7 \%$ de los votos (la ley exigía una mayoría de $60 \%$ de votos).

4 La iniciativa comenzó en Oregon con una prueba piloto que consistió en reunir a unos 24 ciudadanos sorteados a discutir sobre dos propuestas de referéndums. Los resultados fueron tan satisfactorios que en 2011 se aprobó una ley que crea una comisión permanente (bajo la órbita del Ejecutivo) encargada de instrumentar los sorteos y llevar a cabo toda la labor administrativa, que ahora serán convocadas en todas las elecciones locales, siempre que haya propuestas de plebiscitos o referéndum (véase Gastil y Knobloch, 2010; Knobloch et. al, 2014). 


\subsection{Cámara alta o Asamblea permanente de sorteados}

Existe otra línea interesante de complementariedad del sorteo con las elecciones populares, que plantea la creación de organismos o agencias permanentes dentro del proceso de elaboración y aprobación de políticas públicas. La propuesta más recurrente es la de crear una cámara alta de ciudadanos sorteados (véase Callenbach y Phillips, 1985; Sutherland, 2008, 2011; Barret y Carter, 1998; Zakaras, 2010). En algunas propuestas los ciudadanos estarían obligados a participar, mientras que los seleccionados podrían presentar proyectos de leyes y formar coaliciones estables (incluso agruparse en "partidos"). Las decisiones se tomarían por mayoría absoluta de votos y la Cámara podrá vetar por mayoría las propuestas iniciadas en la Cámara de Diputados (Callenbach y Phillips, 1985). En otras propuestas, en cambio, la cámara de sorteados en ningún caso podrá formalmente presentar proyectos, pero tendrá poder de veto. Podrá forzar un plenario en la Cámara de Diputados cuando exista una propuesta que está siendo deliberadamente retrasada (Sutherland, 2008).

En otra línea algo distinta, John McCormick (2011), inspirado en el pensamiento de Maquiavelo (Discursos, 1518) ha propuesto resucitar la figura del "Tribuno de la Plebe" de la república Romana, bajo el formato de una "Asamblea de sorteados". Se trataría de crear un órgano extra-poder, que se sumaría a las ramas de gobierno ya existentes (cámara de representantes, cámara de senadores, poder ejecutivo, poder judicial) y tendría unas competencias limitadas: ejercer un veto por año y convocar un referéndum por año, e iniciar juicio político contra funcionarios federales. La Asamblea no sería estrictamente representativa, porque las personas con ingresos superiores a un determinado umbral quedarían excluidas. El cometido de la propuesta es el de combatir la perversa incidencia del dinero y el poder económico en el proceso político, con capacidad para resistir y neutralizar el sesgo plutocrático de las elecciones.

Es importante preguntarse en qué sentido alguna de estas propuestas promueve la generación, en los participantes, de preferencias autónomas, informadas, y orientadas al bien común. La pregunta es primordial para quienes defienden una teoría de la democracia que aspira a incentivar la conducta pro-social y la participación informada. Las motivaciones no son un problema cuando las asambleas son puntuales y "ad hoc", es decir, cuando tienen una agenda específica y un tiempo muy limitado de actuación. En esas condiciones, es fácil introducir vectores tendientes a potenciar las motivaciones apropiadas. Cuando las asambleas son permanentes y con agendas "abiertas", entonces sí, los sorteados enfrentarían un entorno menos propicio para la generación de preferencias informadas y orientadas al bien común. Otro de los puntos más difíciles de resolver es el del carácter voluntario u obligatorio de la selección aleatoria. Es decir, ¿debe el sorteo aplicarse a los ciudadanos que hayan manifestado su deseo de participar, o éste debe aplicarse a todos (y los ciudadanos tendrán el deber de ocupar el cargo una vez sorteados)? Si lo primero, entonces la muestra no es representativa de la sociedad, y exhibirá un sesgo de sobrerrepresentación de quienes son más activos y ostenten un mayor interés en política. Pero el mayor interés redundará en beneficio de mejores decisiones. Si lo segundo, entonces la muestra será representativa, pero previsiblemente ostentará un menor valor epistémico, producto del menor interés y motivación de los sorteados. 


\section{Un nuevo horizonte de legitimidad democrática: las asambleas de sorteados en referéndums activados por la ciudadanía: Dos propuestas}

Habiendo argumentado a favor de la primacía de las elecciones populares, cabe hacerse la siguiente pregunta: si resulta que algunos diseños de elecciones populares que se complementan con el sorteo resguardan en mejor medida los valores del ideal democrático ¿podríamos sostener que la legitimidad democrática reside en ese sistema mixto? ¿O deberíamos seguir sosteniendo que la legitimidad anida sólo en las elecciones populares y que a lo sumo ese sistema mixto sólo volvería al régimen más democrático? Si pudiéramos demostrar que algún uso complementario del sorteo mejora alguno de los valores que dan sentido a la idea de democracia, ¿deberíamos requerir ese uso como condición necesaria de la legitimidad democrática?

Tengo la impresión de que las asambleas informativas de sorteados, bajo mecanismos de referéndums apropiados iniciados por la ciudadanía, son capaces de fijar un nuevo umbral de legitimidad democrática, y así lo sostengo y argumento en mi último libro (Linares, 2017). Creo que estas asambleas no configuran meramente un "lujo" o, un elemento de mejora de la calidad de la democracia, sino que vienen a añadir una nueva condición necesaria de legitimidad democrática, siempre que acompañen a un adecuado sistema de democracia directa iniciado desde abajo, en el que se prohíban los plebiscitos, en particular los plebiscitos activados por el poder ejecutivo (como sucede en Suiza). Un adecuado sistema de democracia directa iniciado por la ciudadanía mejoraría significativamente el valor de la igual libertad de elección.

Según creo, las asambleas ciudadanas de sorteados, bajo un régimen de voto voluntario en referéndums, están capacitadas para atemperar algunos peligros de las iniciativas populares: ignorancia del votante, seguimiento acrítico a las élites, baja participación, y captura del sistema por grupos de interés. Al ser constituidas por ciudadanos sorteados, sus miembros serían más propensos a suscribir visiones independientes en torno al tema sobre el que se le pide opinión. Asimismo, esa opinión serviría de fuente de consulta para los votantes: muestra cómo un grupo de ciudadanos "comunes" y legos en la materia, pueden llegar a una decisión informada si tuviesen el tiempo de escuchar a los expertos y deliberar entre ellos. Ofrecen, de esta manera, una fuente informativa con credenciales de independencia y diversidad cognitiva que las distingue claramente de las fuentes provistas por los medios masivos de comunicación. Si la opinión del jurado o asamblea es distinta a la predominante en los medios, los votantes tendrán que hacer un esfuerzo cognitivo superior, o decidir a quién confiar su juicio, pensando en los intereses en juego y la neutralidad de cada fuente.

En este punto es posible ensayar los trazos genéricos de dos grandes opciones. En una primera opción institucional, cuyos fundamentos podrían remontarse a Condorcet (en su Plan de Constitución para la República, 1793), una asamblea de sorteados podría reemplazar al típico proceso de recogimiento de firmas. Bajo este sistema, bastaría con presentar un número de firmas muy inferior (e.g. 1000 firmas) al que se exige actualmente (e.g. en Suiza se exigen 50.000 firmas para activar un referendo abrogatorio), pero los promotores tendrán la obligación de financiar una asamblea de sorteados. La convocatoria y la logística de la asamblea estarán a cargo, sin embargo, de un organismo estatal independiente. La asamblea de sorteados en este caso tendrá la obligación de "autorizar" o rechazar la iniciativa propuesta por el grupo promotor. 
Dado que organizar una asamblea de sorteados puede ser muy costoso, el peligro es que este canal termine siendo utilizado por grupos económicos cuando sus preferencias no encuentren respuesta en el sistema representativo. Sin embargo, es importante analizar ese peligro en contexto. En los estados que autorizan las iniciativas ciudadanas de referéndum, el recogimiento de firmas demanda ingentes sumas de dinero (que con mucha frecuencia superan los millones de dólares) y es práctica que los grupos promotores contraten a empresas privadas el recogimiento de firmas. En los Estados Unidos se ha intentado alguna vez prohibir esa práctica, pero la Corte Suprema lo ha declarado inconstitucional por interferir con la libertad de expresión, al amparo de la famosa sentencia en Buckley vs. Valeo (que autoriza la financiación privada indiscriminada en las campañas electorales siempre que haya revelación pública plena de la identidad de los donantes). Con todo, un porcentaje menor de causas ciudadanas son promovidas recurriendo al trabajo voluntario. Pues bien, mi propuesta también es igual de vulnerable al peligro de captura, pero para atemperar este riesgo planteo el siguiente remedio. Sugiero la idea de que - una vez reunido el umbral de firmas mínimoel dinero sólo se pueda recoger por voluntarios -identificados y registrados- en una colecta que habría de utilizar cajas o urnas pequeñas selladas y refrendadas por el Estado, hasta que venza un determinado plazo legal. Los donantes deberán registrarse al aportar, y sus nombres no pueden aparecer en más de una urna. Cada caja o urna debería estar refrendada, además, por un número determinado de firmas. De esa manera, el sistema alentaría la desconcentración de donantes y volvería más complicado para los grandes grupos económicos reunir el requisito con solo aportar el monto total de la donación (podrán hacerlo, pero además de depositar el dinero en cada una de las cientos de urnas tendrán que convencer a cientos de personas a que firmen las urnas). Si el dinero alcanza para sufragar una asamblea de sorteados, se lleva a cabo. Si no pasa un determinado umbral mínimo, el dinero se destina a alguna finalidad de bien común prefijada por ley. La asamblea de sorteados trataría la cuestión durante una semana, y tendrá la obligación de autorizar o no el referéndum. Si lo autoriza, la iniciativa se gira al Congreso, que debe aprobarla, enmendarla o rechazarla. Si las enmiendas son aceptadas por el grupo promotor, la iniciativa se aprueba como ley. Si no lo son, o el Congreso rechaza la iniciativa, se somete a referéndum.

La otra opción es la instrumentada por el Estado de Oregon: emplear jurados ciudadanos informativos para que los votantes en referéndum puedan informarse de cómo una asamblea de sorteados decidiría la cuestión. Bajo este sistema el Estado correría con los costos de los jurados, que por razones económicas serían menos numerosos (y menos representativos) y eventualmente podrían tratar más de un asunto si las propuestas son múltiples. El esquema de Oregón incluso podría perfeccionarse, porque se ha demostrado que sólo la mitad de los votantes acuden a las guías del votante para informarse (Bowler y Donovan, 2002). En ese sentido, se podría consignar, detrás de la papeleta del voto, la decisión del jurado y sus argumentos, y la decisión de la mayoría del Congreso y sus argumentos (véase Linares, 2017, capítulo VII).

No existe ninguna buena razón para permitir que las disparidades de riqueza se trasladen a las disparidades en poder político (Sunstein, 1994). Mi propuesta, en particular la versión Condorcetiana de democracia directa, intenta llevar a la práctica esa aspiración. Creo que ahí reside el lugar en el que el sorteo puede acomodarse con el ideal de autogobierno y la libertad de elección que son inherentes a nuestra comprensión moderna de la democracia. 


\section{Conclusiones}

He argumentado que son tres los valores implicados en la legitimidad de las leyes, así que debemos preguntarnos cómo es que el sorteo se ajusta a los mismos. El sorteo de cargos públicos resulta plenamente congruente con el valor de la igualdad de trato, puesto que concede a todos una igual probabilidad de obtener un cargo público. Sin embargo, parece lesionar el valor de la libertad de elegir cuando el número de cargos sorteado es reducido, en tanto que las personas sometidas a coerción estatal no ejercen ninguna influencia ni tienen ninguna posibilidad de manifestar su libertad de elección respecto de quién terminará obteniendo el cargo. Esta ausencia de la libertad de elección pone al sorteo puro de cargos públicos en serios aprietos si queremos adjudicarle la autoridad final, puesto que es razonable argumentar que no queremos vivir bajo leyes sobre las que no hemos podido manifestar nuestra libertad de elección. Según creo, este argumento comporta una objeción suficiente para rechazar el sorteo de cargos como mecanismo sustitutivo de las elecciones de gobernantes. Sin embargo, no alcanza por sí sólo para rechazar esquemas mixtos de gobierno, en los que las elecciones se combinan con el sorteo de cargos públicos.

Mi argumento, no obstante, es que las elecciones populares han de ser complementadas con mecanismos adecuados de democracia directa iniciados por la ciudadanía, y es en el marco de esos mecanismos que, según creo, las asambleas de sorteados (bien autorizando las iniciativas, bien informando al votante) fijan un nuevo horizonte o umbral de legitimidad democrática para los nuevos tiempos que corren. El desafío es cómo incorporarlas de tal manera que se propicie la participación ciudadana informada, autónoma y orientada al bien común.

\section{Referencias}

Baldassarri, Delia y Guy Grossman (2011): "Centralized sanctioning and legitimate authority promote cooperation in humans". Proceedings of the National Academy of Sciences, Vol. 108 (27), pp. 1023-7.

Barnett, Anthony y Peter Carty (2008): The Athenian Option: Radical Reform for the House of Lords. Exeter: Imprint Academic.

Bowler, Shawn y Todd Donovan (2002): "Do Voters Have a Cue? Television Advertisements as a Source of Information in Citizen-Initiated Referendum Campaigns". European Journal of Political Research, Vol. 41 (6), pp. 777-792.

Brennan, Jason (2014): "How Smart is Democracy? You Can't Answer that Question a Priori". Critical Review. A Journal of Politics and Society. Vol. 26, (1.2), pp. 33-58.

Brennan, Jason (2016): Against Democracy. Princeton University Press.

Callenbach, Ernest y Michael Phillips (1985): A Citizen Legislature. Berkeley, CA: Banyan Tree Books.

Condorcet, Nicolás (1793): An Authentic Copy of the New Plan of the French Constitution. London: J. Debrett, 1793.

Elster, Jon y Hélène Landemore (eds.) (2010): Collective Wisdom: Principles and Mechanisms. Cambridge: Cambridge University Press. 
Fishkin, James (2009): When the People Speak: Deliberative Democracy \& Public Consultation. Oxford: Oxford University Press.

Fishkin, James (2010): "Response to Critics of When the People Speaks: The Deliberative Deficit and What to Do About It". The Good Society, Vol. 19 (1), pp. 68-76.

Garret, Elizabeth y Matthew Mccubbins (2007): "The Dual Path Initiative Framework". Southern California Law Review, 2007, Vol. 80, pp. 299-346.

Gastil, John y Katherine Knobloch (2010): Evaluation Report to the Oregon State Legislature on the 2010 Oregon Citizens' Initiative Review. Salem, OR: Oregon House Rules Committee, 2010.

Gastil, John y Robert Richards (2012): "Making Direct Democracy Deliberative through Random Assemblies". Artículo presentado en el Congreso anual de la American Sociological Association, en Denver, Colorado.

Hong, Lu y Scott Page (2001): "Problem solving by heterogeneous agents". Journal of Economic Theory, Vol. 97 (1), pp. 123-163.

Hong, Lu y Scott Page (2004): "Groups of diverse problem solvers can outperform groups of high-ability problem solvers". Proceedings of the National Academy of Sciences, Vol. 101 (46), pp. 16385-16389.

Hong, Lu y Scott Page (2012): "Some Microfoundations in Collective Wisdom”. En Landemore, Helene y Jon Elster (2012): Colllective Wisdom: Principles and Mechanisms. Yale University Press: pp. 251-290.

Knobloch, Katherine, John Gastil, Traci Feller y Robert Richards (2014): "Empowering Citizen Deliberation in Direct Democratic Elections: A Field Study of the 2012 Oregon Citizens' Initiative Review". The Journal of Field Action Science Reports. Special Issue 11. Disponible en: https://factsreports.revues.org/3448

Lafont, Cristina (2014): "Deliberation, Participation, and Democratic Legitimacy: Should Deliberative Mini-publics Shape Public Policy?". The Journal of Political Philosophy, Vol. 23 (1), pp. 1-24.

Landemore, Hélène (2013a): "Deliberation, cognitive diversity, and democratic inclusiveness: an epistemic argument for the random selection of representatives". Synthese, Vol. 190 (7), pp. 1209-1231.

Landemore, Hélène (2013b): Democratic Reason. Politics, Collective Intelligence, and the Rule of the Many. Princeton University Press.

Landemore, Hélène (2014): "Yes, We Can (Make It Up on Volume): Answers to Critics". Critical Review. A Journal of Politics and Society, Vol. 26 (Issue 1-2), pp. 184-237.

Linares, Sebastián (2017): Democracia participativa epistémica. Madrid: Marcial Pons.

Martí, José Luis (2006a): “The Epistemic Conception of Deliberative Democracy Defended”. En Besson, Samantha y José Luis Martí (2006). Deliberative democracy and its discontents, Capítulo 2. Londres: Routledge.

Martí, José Luis (2006b): La república deliberativa. Madrid: Marcial Pons.

McCormick, John (2011): Machiavellian Democracy. NY: Cambridge University Press.

Page, Scott (2007): The Difference: How the Power of Diversity Creates Better Groups, Firms, Schools and Societies. Princeton, NJ: Princeton University Press.

Page, Scott (2007b): "Making the Difference: Applying a Logic of Diversity". Academy of Management Perspectives, 2007, November, pp. 6-7. 
Sintomer, Yves (2007): Le Pouvoir au Peuple: Jurys Citoyens, Tirage au Sort et Democratie Participative. París: La Decouverte.

Sintomer, Yves (2010a): "Random Selection and Deliberative Democracy". In G. Delannoi, Gil y Oliver DOWLEN (eds.) (2010): Sortition: Theory and Practice Exeter: Imprint Academic, pp. 31-51.

Sintomer, Yves (2010b): "Random Selection, Republican Self-Government, and Deliberative Democracy". Constellations, Vol. 17 (3), pp. 472-487.

Sunstein, Cass (1994): Political Equality and Unintended Consequences. Columbia Law Review, Vol. 94: pp. 1390-1400.

Sutherland, Keith (2008): A People's Parliament. Exeter: Imprint Academic.

Sutherland, Keith (2011): "The Two Sides of the Representative Coin". Studies in Social Justice, Vol. 5 (2), pp. 197-211.

Zakaras, Alex (2010): "Lot and Democratic Representation: A Modest Proposal”. Constellations, Vol. 17 (2), pp. 455-471. 